\title{
Secondary adrenal insufficiency caused by sorafenib administration in a patient with hepatocellular carcinoma
}

\author{
Soo Yeon Jo, Soo Hyung Ryu, Mi Young Kim, Jeong Seop Moon, Won Jae Yoon, Jin Nam Kim \\ Department of Internal Medicine, Seoul Paik Hospital, Inje University College of Medicine, Seoul, Korea
}

\begin{abstract}
Sorafenib (Nexavar) has been regarded as a treatment for unresectable hepatocellular carcinoma (HCC), with side effects that include hand-foot skin reaction, diarrhea, rash, fatigue, hypertension, nausea, anorexia, weight loss, and alopecia. Thyroid disorder, such as endocrine side effect, has also been reported. However no case involving adrenal insufficiency has been reported. Here, we report a case of adrenal insufficiency which occurred after taking sorafenib in a patient with HCC. A 56-year-old man visited our hospital due to right upper quadrant abdominal pain and he was diagnosed as multiple disseminated and unresectable HCCs with portal vein invasion; therefore transarterial chemoembolization was performed and sorafenib administration was started. Two months later, he was admitted to the hospital complaining of severe fatigue. The laboratory results showed cortisol of $<0.2 \mu \mathrm{g} / \mathrm{dL}$ and adrenocorticotropic hormone of $<1.00 \mathrm{pg} / \mathrm{mL}$. The patient had no history of taking steroids or herbal medications. Secondary adrenal insufficiency was diagnosed and prednisolone $10 \mathrm{mg}$ per day was started immediately; as a result, fatigue remarkably improved. This may be the first report indicating a possible association between sorafenib and adrenal insufficiency and it implies that the possibility of adrenal insufficiency should be considered in patients taking sorafenib who complain of severe fatigue.
\end{abstract}

Keywords: Hepatocellular carcinoma; Sorafenib; Adrenal insufficiency; Adverse effects

\section{INTRODUCTION}

Hepatocellular carcinoma (HCC) is the fifth most prevalent cancer worldwide and the third leading cause of cancer mortality [1]. Sorafenib (Nexavar), which has been regarded as a drug for treatment of patients with unresectable or advanced HCC and it may have side effects, including hand-foot skin reaction, diarrhea, rash, fatigue, and hypertension, etc. [2]. Thyroid disorders such as endocrine side effects have also been

Received: May 23, 2015, Revised: July 28, 2015

Accepted: July 28, 2015

Corresponding Author: Soo Hyung Ryu, Department of Internal Medicine, Seoul Paik Hospital, Inje University College of Medicine, 9, Mareunnae-ro, Jung-gu, Seoul 04551, Korea Tel: +82-2-2270-0012, Fax: +82-2-2279-4021

E-mail: rshdrryu@medimail.co.kr reported, however no case involving adrenal insufficiency has been reported [3]. Here we report a first case of secondary adrenal insufficiency which occurred after taking sorafenib in a patient with HCC.

\section{CASE}

A 56-year-old man was referred to our hospital due to right upper quadrant abdominal pain. The patient had a history of chronic hepatitis B and heavy alcohol drinking. Abdominal computed tomography (CT) showed multiple disseminated tumors in the entire liver, which were invading the portal vein and were unresectable (Fig. 1). A liver biopsy for the masses in the liver revealed HCC. Transarterial chemoembolization (TACE) was performed immediately. Sorafenib was also started at a dosage of $400 \mathrm{mg}$ b.i.d. As the size and numbers of

Copyright (C) 2016 Yeungnam University College of Medicine

This is an Open Access article distributed under the terms of the Creative Commons Attribution Non-Commercial License (http://creativecommons.org/licenses/by-nc/4.0/) which permits unrestricted non-commercial use, distribution, and reproduction in any medium, provided the original work is properly cited. 
HCC increased on follow up abdominal CT and background liver function was not poor, we did TACE 3 times over 2 months. Two months after administration of sorafenib, the patient complained of severe fatigue and general weakness. He was not able to walk by himself or perform daily activity. He had no history of diarrhea, vomiting, or fever, and his oral intake was not poor. He was admitted to the hospital for further evaluation and treatment. His blood pressure was 103/ $74 \mathrm{mmHg}$, pulse rate was 125 beats/min, and temperature was $37.0^{\circ} \mathrm{C}$. The laboratory results showed hemoglobin $11.9 \mathrm{~g} / \mathrm{dL}$, white blood cell $5,240 / \mu \mathrm{L}$, platelet $474,000 / \mu \mathrm{L}$, sodium 134 $\mathrm{mmol} / \mathrm{L}$, potassium of $4.6 \mathrm{mmol} / \mathrm{L}$, glucose $128 \mathrm{mg} / \mathrm{dL}$, aspar-
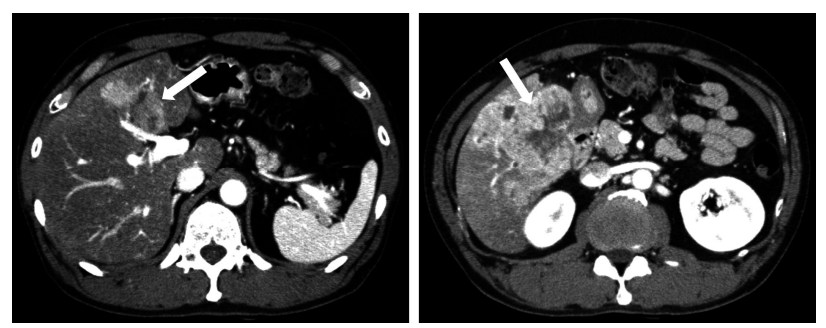

Fig. 1. Abdominal computed tomography shows multiple hepatocellular carcinomas in the entire liver with extensive involvement of segment 5 .

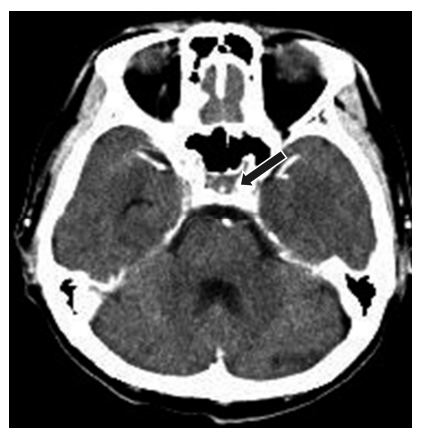

Fig. 2. Sella computed tomography shows intact hypothalamic-pituitary gland structure.

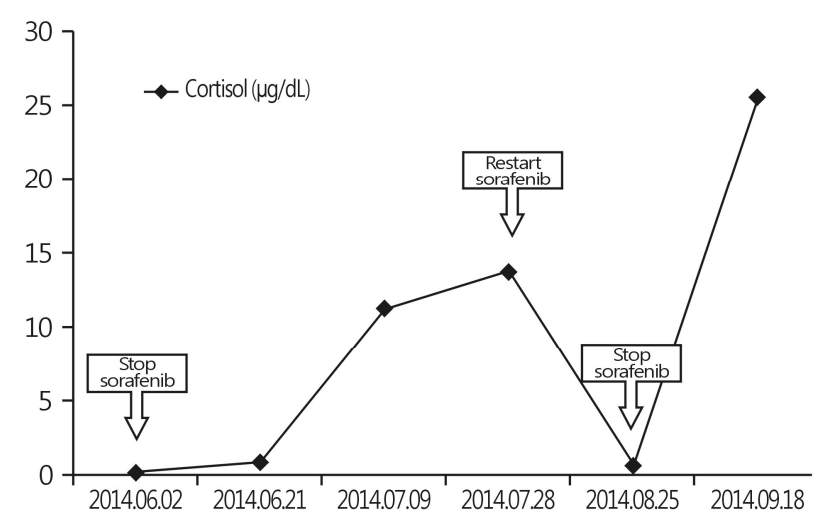

Fig. 3. Cortisol level increased after stop taking sorafenib. tate aminotransferase $75 \mathrm{IU} / \mathrm{L}$, alanine aminotransferase 31 $\mathrm{IU} / \mathrm{L}$, total bilirubin $0.5 \mathrm{mg} / \mathrm{dL}$, albumin $3.0 \mathrm{~g} / \mathrm{dL}$, prothrombin time $14.2 \mathrm{sec}(79 \%)$ ), cortisol $<0.2 \mu \mathrm{g} / \mathrm{dL}$ (range, 6.2-19.4 $\mu \mathrm{g} /$ $\mathrm{dL}$ ), adrenocorticotropic hormone (ACTH) $<1.00 \mathrm{pg} / \mathrm{mL}$ (range, 7.2-63.3 pg/mL), thyroid stimulating hormone (TSH) 4.0139 $\mu \mathrm{IU} / \mathrm{mL}$ (range, $0.35-4.94 \mu \mathrm{IU} / \mathrm{mL}$ ), and $\mathrm{T} 46.38 \mu \mathrm{g} / \mathrm{dL}$ (range, 4.87-11.72 $\mu \mathrm{g} / \mathrm{dL}$ ). There was no recent medication history of steroids or herbal medication. A sella CT performed for evaluation of anatomical abnormalities of hypothalamic-pituitary gland showed intact structure (Fig. 2). Secondary adrenal insufficiency was diagnosed and sorafenib medication was stopped immediately, while prednisolone $10 \mathrm{mg}$ per day was started. Fatigue symptoms remarkably improved and the level of cortisol and ACTH increased. Twenty days after stopping sorafenib, the laboratory results showed cortisol $0.85 \mu \mathrm{g} / \mathrm{dL}$ and ACTH $1.46 \mathrm{pg} / \mathrm{mL}$, and 40 days after, the level of cortisol showed $11.18 \mu \mathrm{g} / \mathrm{dL}$ and ACTH $25.61 \mathrm{pg} / \mathrm{mL}$ (Fig. 3). He was able to walk by himself and to perform daily activity soo- ner. He continued to stop taking sorafenib and was discharged with medication of $10 \mathrm{mg}$ per day of prednisolone.

Two months after stop taking sorafenib, the follow up laboratory results was checked at cortisol $13.67 \mu \mathrm{g} / \mathrm{dL}$, ACTH $<1.00 \mathrm{pg} / \mathrm{mL}$, TSH $2.4547 \mu \mathrm{IU} / \mathrm{mL}$, and free T4 $0.96 \mathrm{ng} / \mathrm{dL}$ (range, $0.70-1.48 \mathrm{ng} / \mathrm{dL}$ ). Therefore sorafenib was restarted at a dosage of $400 \mathrm{mg}$ q.d. and prednisolone was tapered to a dosage of $5 \mathrm{mg}$ q.d.. One month after readministration of sorafenib, the patient came to hospital with general weakness again. At that time, the laboratory results showed cortisol $0.64 \mu \mathrm{g} / \mathrm{dL}$, ACTH $<1.00 \mathrm{pg} / \mathrm{mL}$, TSH $2.1896 \mu \mathrm{IU} / \mathrm{mL}$, and free T4 $0.78 \mathrm{ng} / \mathrm{dL}$. After taking sorafenib was stopped again, general weakness was improved dramatically and the cortisol level was elevated to $31.43 \mu \mathrm{g} / \mathrm{dL}$ (Fig. 3).

\section{DISCUSSION}

Over 650,000 people die from HCC each year worldwide; at least two-thirds of deaths occur in East Asia [4]. TACE is a treatment modality for patients with unresectable HCC $[5,6]$. Sorafenib can target TACE-induced angiogenic factor and potentially enhance its efficacy, and significantly improved efficacy has been reported for the combination therapy of sorafenib and TACE in advanced HCC [7].

Sorafenib, a multi-tyrosine kinase inhibitor that targets vascular endothelial growth factor receptor, platelet-derived 
growth factor receptor, Raf kinase, c-kit, and RET, can block angiogenesis and tumor growth $[1,7,8]$. It is the first approved molecularly targeted agent for HCC and it is the only systemic treatment which has a statistically significant effect on prolonging overall survival in patients with unresectable or advanced HCC in large phase III randomized, placebo-controlled trials.

In 2008, Llovet et al. conducted trials at 121 centers in 21 countries in Europe, North America, South Ame- rica, and Australasia. In this trial, patients with advanced HCC who received sorafenib treatment had nearly 3 months longer median survival and the time to radiologic progression as compared with those who received placebo. In 2009, Cheng et al. also assessed the efficacy and safety of sorafenib in AsiaPacific patients with advanced HCC. The patients who were randomised to treatment with sorafenib had significantly longer overall survival, prolonged time to progression and improved disease control rate than those who received placebo [8-10].

Frequently reported adverse events of sorafenib include handfoot skin reaction, diarrhea, rash, fatigue, nausea, anorexia, hypertension, weight loss, alopecia, etc. [2]. Regarding endocrine side effects, thyroid disorders have also been reported [3]. In addition, Okushin $\mathrm{K}$ et al. reported a case of a 77-yearold man who showed severe hypoglycemia and hyperkalemia during treatment with sorafenib for advanced HCC. It suggested that there might be two causes of hypoglycemia, adrenal insufficiency due to sorafenib and activation of the insulin-like growth factor (IGF) signal by excessive secretion of incompletely processed precursors of IGF-II. If it were sorafenib-induced adrenal insufficiency, it would be primary adrenal insufficiency because hyperkalemia was observed on initial laboratory results in that case, while our case was secondary adrenal insufficiency caused by sorafenib [11].

In the current case, a 56-year-old man diagnosed as HCC who started sorafenib developed severe fatigue, the level of cortisol and ACTH was severely suppressed at that time. The sella CT showed no abnormality and abdominal CT also showed intact adrenal gland. After discontinuing sorafenib and starting administration of steroids, fatigue symptoms and the levels of cortisol were recovered.

When fatigue occurred, the patient had been taking oxycodone, which is known to be a cause of secondary adrenal insufficiency. However, adrenal insufficiency due to oxycodone administration is known to occur several years after its treatment, therefore the possibility of oxycodone as the cause of adrenal insufficiency is low. Oxycodone medication was stopped when severe fatigue occurred and twenty days later mypol, the drug of combination of codeine, ibuprofen, and acetaminophen was prescripted instead of oxycodone for pain control continuously.

The patient also had been taking viread $300 \mathrm{mg}$ q.d., UDCA and legalon. However, these medications were constantly given to the patient regardless of the cortisol level and fatigue symptom, while the change of symptoms and the cortisol level correlated to taking sorafenib.

TACE was done 3 times for 2 months before and 4 times for 4 months after diagnosis of adrenal insufficiency. Considering of time relation, TACE and adrenal insufficiency does not correlate together which means TACE does not cause adrenal insufficiency. Furthermore, we could not find any case report of TACE-induced adrenal insufficiency.

To the best of our knowledge, this is the first report of secondary adrenal insufficiency developed during sorafenib treatment in a patient with HCC. This case suggests that sorafenib could induce secondary adrenal insufficiency, therefore, adverse effects of adrenal insufficiency should be considered in patients taking sorafenib who complain of severe fatigue or general weakness.

\section{REFERENCES}

1. Abdel-Rahman O. Systemic therapy for hepatocellular carcinoma (HCC): from bench to bedside. J Egypt Natl Canc Inst 2013;25:165-71.

2. Keating GM, Santoro A. Sorafenib: a review of its use in advanced hepatocellular carcinoma. Drugs 2009;69:223-40.

3. Feldt $S$, Schüssel K, Quinzler R, Franzmann A, Czeche $S$, Ludwig WD, et al. Incidence of thyroid hormone therapy in patients treated with sunitinib or sorafenib: a cohort study. Eur J Cancer 2012;48:974-81.

4. Asia-Pacific Working Party on Prevention of Hepatocellular Carcinoma. Prevention of hepatocellular carcinoma in the Asia-Pacific region: consensus statements. J Gastroenterol Hepatol 2010;25:657-63.

5. Bruix J, Sala M, Llovet JM. Chemoembolization for hepatocellular carcinoma. Gastroenterology 2004;127(5 Suppl 1): S179-88.

6. Kim H, Kim YH, Yoon HJ, Lee KH, Joo SM, Byun MK, et al. Lipiodol-induced pneumonitis following transarterial chemoembolization for ruptured hepatocellular carcinoma. Yeungnam Univ J Med 2014;31:117-21. Korean.

7. Zhang L, Hu P, Chen X, Bie P. Transarterial chemoembolization (TACE) plus sorafenib versus TACE for intermediate or 
advanced stage hepatocellular carcinoma: a meta-analysis. PLoS One 2014;9:e100305.

8. Llovet JM, Ricci S, Mazzaferro V, Hilgard P, Gane E, Blanc JF, et al. Sorafenib in advanced hepatocellular carcinoma. N Engl J Med 2008;359:378-90.

9. Cheng AL, Kang YK, Chen Z, Tsao CJ, Qin S, Kim JS, et al. Efficacy and safety of sorafenib in patients in the Asia-Pacific region with advanced hepatocellular carcinoma: a phase III randomised, double-blind, placebo-controlled trial. Lancet Oncol 2009;10:25-34.
10. Abdel-Rahman O, Fouad M. Sorafenib-based combination as a first line treatment for advanced hepatocellular carcinoma: a systematic review of the literature. Crit Rev Oncol Hematol 2014;91:1-8.

11. Okushin K, Asaoka Y, Fukuda I, Fujiwara N, Minami T, Sato $\mathrm{M}$, et al. IGF-II producing hepatocellular carcinoma treated with sorafenib: metabolic complications and a foresight to molecular targeting therapy to the IGF signal. Case Rep Gastroenterol 2012;6:784-9. 